\title{
The scientific basis of severe acute pain management in the emergency department
}

\section{INTRODUCTION}

Pain resulting from acute illness or injury has a history as long as that of beings capable $\overrightarrow{\vec{A}}$ of nociception. Pain relief has been the aim of sympathetic humans and of the medical 윽 profession for thousands of years. Physical remedies such as rest, warmth and cold were $\rightarrow$ supplemented by drugs such as opium centuries ago. Technological and pharmaceutical advances have brought us to a situation where we have now a wide variety of drugs and $\stackrel{\Im}{工}$ techniques available to relieve severe acute pain.

Only very recently have the neurophysiology and neuropharmacology of pain relief been elucidated. Information obtained from studying chronic pain and its managemen is now being applied to management of acute pain. This paper sets out the scientifi. basis of the selection of drug, dose and technique in a variety of situations met in the emergency department.

\section{ESSENTIAL NEUROPHYSIOLOGY OF PAIN}

The traditional view that there were anatomically-distinct pain receptors which, when stimulated, sent impulses along afferent nerves to the spinothalamic tract and up the spinal cord to the brain has been replaced by a concept which acknowledges that pain transmission involves complex neural connections.

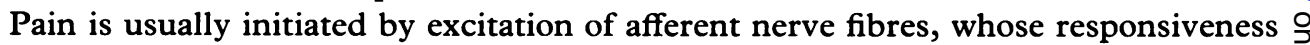
may be increased or decreased by the physical or chemical environment. Acetylsalicylic $\frac{D}{0}$ acid, for example, inhibits cyclo-oxygenase, an enzyme which controls the synthesis of prostaglandins, prostacyclins and thromboxanes, which are involved in pain (Juan, $\widetilde{\sigma}$ 1978).

Pain messages are transmitted by fine myelinated A-delta fibres (immediate pain) and by unmyelinated $\mathrm{C}$ fibres (delayed pain) to the spinal cord via both dorsal and ventral $\underset{0}{0}$ roots (Coggeshall et al., 1975). Within the dorsal horn there are multiple synapses with both ascending and descending fibres. Transmission then proceeds upwards via the spinothalamic and spinoreticular tracts to the brainstem reticular formation, and thence to the medial, posterior and ventral thalamus, cerebral cortex and intralaminar nuclei; 
via the neospinothalamic tract to the contralateral thalamus; and via the paleospinothalamic tract to midline intrathalamic regions. The principle neurotransmitters are dopamine, noradrenaline and 5-hydroxytryptamine.

The importance of the gate control theory of pain (Melzack \& Wall, 1965) was the concept that perception of pain depended not only on the above mechanism, but also on modulation or modification of the pain impulse by both ascending and descending information which could alter the sensory message. Pain may be modulated at the spinal cord level in the brainstem or the thalamus (Fig. 1). Similar mechanisms operate for the trigeminal nerve, and for visceral pain transmission via the sympathatic nervous system. Visceral afferents converge on the same dorsal horn neurones as somatic nociceptive afferents, which accounts for the phenomenon of referred pain. Convergence of visceral afferents on dorsal horns over a wide number of segments results in poor localization of visceral pain (Fig. 2).

A knowledge of the innervation of tissues and organs, of dermatomes, and of areas of the body to which visceral pain is referred is clearly essential to the evaluation of a patient's pain (Phillips \& Cousins, 1986).

\section{PSYCHOLOGY OF PAIN}

Henry Beecher (1945) observed that a high proportion of men wounded in battle felt no pain. He studied 225 freshly-wounded soldiers, considered in five groups: compound fractures of long bones, extensive peripheral soft-tissue wounds, penetrating wounds of the thorax, penetrating wounds of the abdomen and penetrating wounds of the cerebrum. He found that patients with penetrated abdomens had the most pain, that only one quarter of the injured said that their pain was enough to cause them to want pain-relief therapy, and that the man in shock complained far less frequently of wound pain than of the distress produced by thirst.

In a subsequent study, Beecher (1956) compared battlefield wounds with civilian wounds. While $32 \%$ of the war-wounded desired narcotics, $83 \%$ of the civilian wounded did so. Beecher attributed this difference to the fact that the war-wounded saw injury as meaning escape from anxiety and fear of death, whereas the civilian saw it as a personal disaster. More recently, Melzack et al. (1982) found that $37 \%$ of patients attending an emergency department felt no pain following injury, and some did not feel pain for up to 9 hours following injury. They discussed four factors which may influence presence of a pain-free period: the circumstances at the time of injury, the state of the patient, their personality and the nature of the injury. The predominant emotions of the patient were embarrassment at appearing careless or worry about loss of wages. None expressed any pleasure, or indicated any prospect of gain as a result of the injury.

Peck (1986) has described many of the factors influencing a patient's behaviour in response to pain. There are cultural differences in pain behaviour, probably learned as a child. Children also learn how to respond to pain by observing parents and older siblings. The meaning of pain is important in that a pain interpreted as indicating severe disability or possibly death results in a different response to pain considered no threat. 


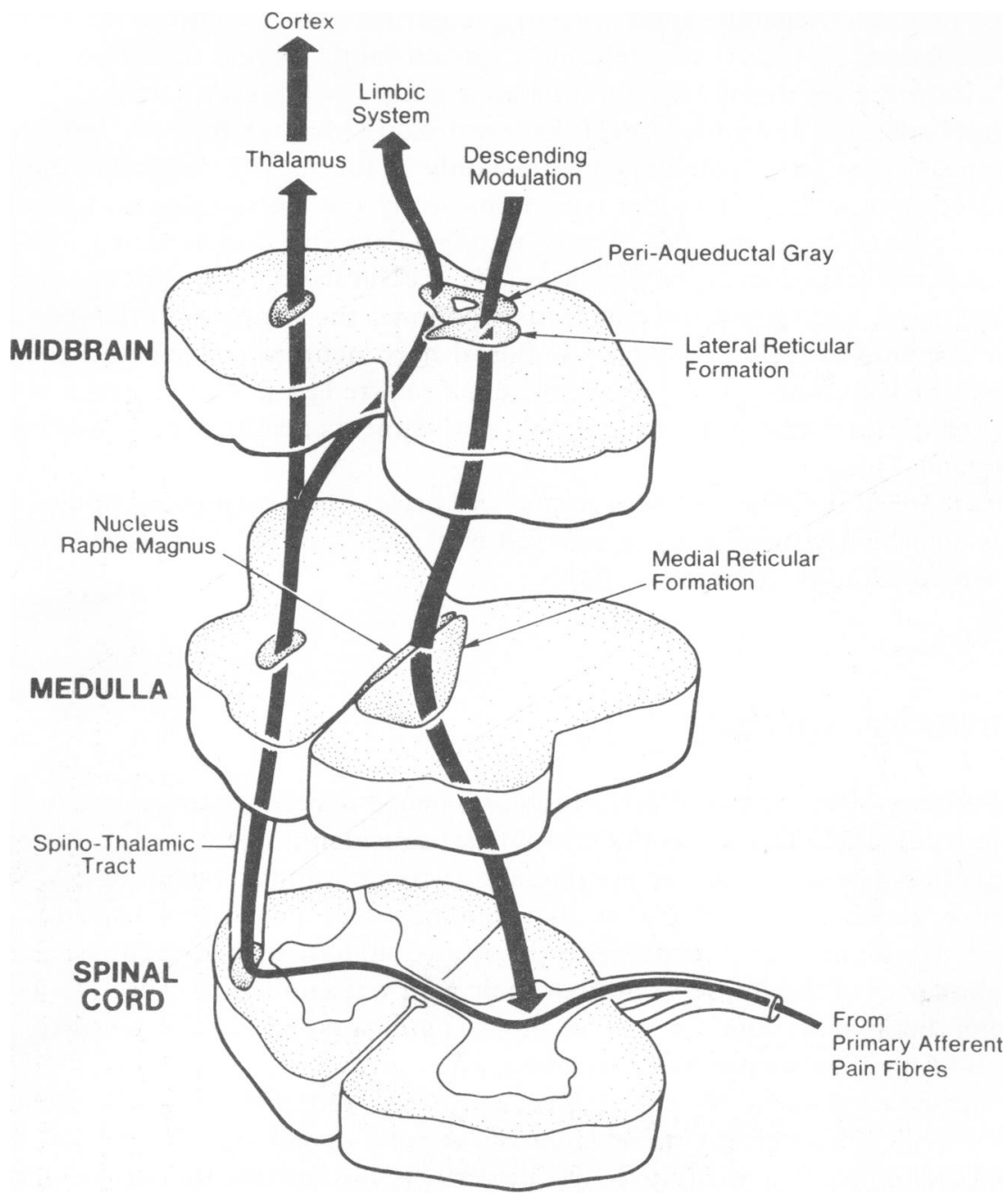

Fig. 1. Modulation of pain at spinal cord, medulla and midbrain.

Note initial modulation in dorsal horn of spinal cord. Descending modulation is initiated in the peri-aqueductal grey matter, in the medial and lateral reticular formation, and in the nucleus raphe magnus. Descending inhibitory tracts in the dorsolateral fasciculus then impinge on dorsal horn and release several inhibitory neurotransmitters. The main afferent pain pathway ascends via thalamus to the cerebral cortex, probably to produce the 'physical' aspects of pain. An offshoot relays to the limbic system, probably resulting in the 'emotional' aspects of pain.

(Reproduced with permission from Cousins \& Philips [1986].)

Fear and anxiety have been related to the degree of pain experienced. Other relevant factors may include the patient's personality, their perceived control over their condition and their coping style. Pain perception is also influenced by attention to, or distraction from, the painful stimulus. 
Editorial 7

곡
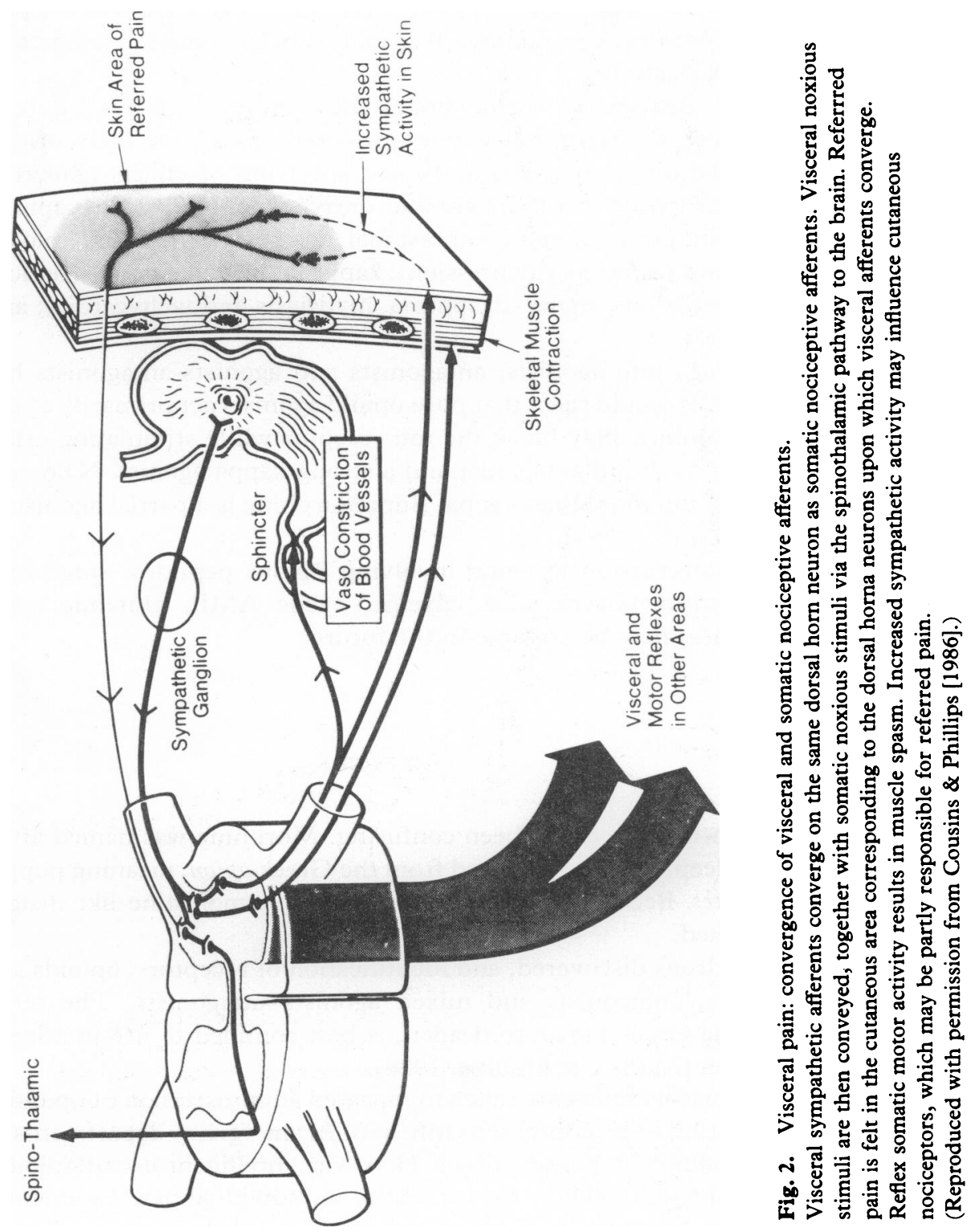

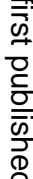

क

$\vec{\circ}$

$\overrightarrow{\vec{\omega}}$

$\frac{10}{3}$

i

$\vec{A}$

옹

$\overrightarrow{3}$

$\stackrel{3}{3}$

$\vec{\circ}$

8.

웅

흑으

잉

$\stackrel{8}{2}$

음

三

จ

훙

อิ

임

음

N

N

₹

음

$\stackrel{\mathbb{\infty}}{\stackrel{9}{+}}$

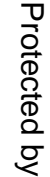




\section{PAIN NEUROPHARMACOLOGY}

Traditionally, pain relief has depended either upon blockade of afferent pathways by

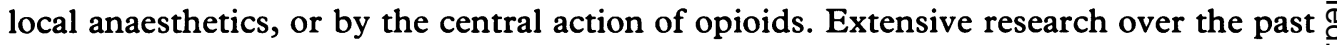
few years has revealed the presence of a number of opioid receptors, and of endogenous peptides with morphine-like activity.

Opioid receptors are distributed throughout the central nervous system. Subdivisions of opioid receptor-types have been proposed, based on their origin, affinity for specific drug binding, cross-reactivity and spectrum of effects (Zukin $\&$ Zukin, 1981). It has been proposed that there are four or five types of opioid receptors: mu and delta (involved in production of supraspinal analgesia, euphoria, miosis, $\vec{\circ}$ dependence, bradycardia and respiratory depression); kappa (spinal analgesia, sedation, miosis and respiratory depression); sigma (dysphoria, mydriasis and tachycardia); and epsilon (Ling et al., 1983).

The classification of drugs into agonists, antagonists and agonists-antagonists has been based on this concept. It would seem that pure opioid agonists act primarily as the mu receptor, whereas nalorphine may block the mu receptor while stimulating other receptors. Pentazocine is a weak mu antagonist and a strong kappa agonist. Naloxone antagonizes both receptors, mu more than kappa. Buprenorphine is a partial agonist at the mu receptor (Paterson et al., 1983).

Modification of pain-transmission systems involving opioid peptides, serotonin, noradrenaline, gamma hydroxybutyric acid, glycine, cyclic AMP, glutamic acid, neurotensin and somatostatin may be possible in the future.

\section{OPIOIDS}

The terminology of opium-like drugs has been confusing. Morphine was named after Morpheus, Greek god of sleep. Opium is derived from the Greek opion, meaning poppy juice, hence the term opiates. Because of the advent of synthetic morphine-like drugs, the term 'opioids' was coined.

Because of the range of drugs discovered, and identification of receptors, opioids are now divided into agonists, antagonists and mixed agonists-antagonists. The term 'narcotic', derived from the Greek narco, to deaden, is best confined to use in a legal sense for drugs of addiction (Mather \& Phillips, 1986).

Most of the recent pharmacokinetic data relate to repeated administration of opioids, either by intermittent injection or by continuous infusion. In emergency departments it is much more common to administer single doses. However, intelligent use of opioids depends upon a flexible approach to allow for variability in individual pain experience and tolerance, as well as the beneficial and adverse effects of the drug used.

This requires knowledge of how the body handles the drug, i.e. rate of absorption, distribution, biotransformation and elimination (pharmacokinetics), and what the drug does to the body, especially information on the relationship between pharmacological responses and drug concentrations (pharmacodynamics). Key definitions found in the literature include: 
Table 1 Opioid pharmacokinetic and related data

\begin{tabular}{lcll}
\hline & $\begin{array}{l}\text { Intravenous } \\
\text { potency ratio }\end{array}$ & $\begin{array}{l}\text { Distribution } \\
\text { half-life } \\
\text { (minutes) }\end{array}$ & $\begin{array}{l}\text { Elimination } \\
\text { half-life } \\
\text { (hours) }\end{array}$ \\
\hline Fentanyl & 292 & $2 \cdot 3$ & $2-5$ \\
Alfentanil & 73 & 3 & $1 \cdot 3-3 \cdot 3$ \\
Pethidine & $0 \cdot 53$ & $4 \cdot 2-11 \cdot 4$ & $3-7$ \\
Morphine & 1 & 25 & $1 \cdot 4-4$ \\
Methadone & 1 & 10 & $25-45$ \\
Buprenorphine & 33 & 3 & $2-4 \cdot 5$ \\
\hline
\end{tabular}

(Modified from Mather \& Phillips [1986].)

Opioid pharmacokinetics are altered by age, with prolongation of half-life in neonates and the elderly, by liver disease and by low cardiac output states.

A variety of new fentanyl derivatives has become available, including sufentanil, lofentanil and alfentanil. The latter has a small volume of distribution and short terminal half-life due to low tissue solubility (Mather, 1983).

Agonist-antagonist drugs are of limited interest. Pentazocine, nalbuphine, butorphenol and buprenorphine have 'ceiling effects' on both respiratory depression and analgesia. Buprenorphine may antagonize its own analgesic effect, and respiratory depression is only partially reversed by naloxone (Bullingham et al., 1983). 
The enkephalin analogue metkephamid is the first of a new series of analgesic agents to have undergone clinical trials. A dose equianalgesic with $100 \mathrm{mg}$ pethidine had a longer duration of action and a different side-effect profile (Rosow, 1985).

Side effects of opioids include respiratory centre depression resulting in decreased respiratory rate and tidal volume, with a shift of the $\mathrm{CO}_{2}$ response curve; vasodilation and hypotension; decreased intestinal motility, spasm of the sphincter of Oddi; central nervous system excitation (pethidine, fentanyl); and sedation, miosis, nausea, vomiting and pruritis (Gourlay \& Cousins, 1984).

\section{LOCAL ANAESTHETIC AGENTS}

Although the earlier local anaesthetic agents were esters, those most commonly used today are the amides prilocaine, lignocaine, mepivacaine, bupivacaine and etidocaine. These are dispensed as hydrochloride salts, which are ionized and water soluble at body $\mathrm{pH}$. Rapidity of onset of action is related to chemical structure, whereas long duration of action is associated with high lipid solubility (Mather \& Cousins, 1979).

Local disposition of local anaesthetic depends on bulk flow of the injected solution along tissue planes, diffusion across lipid barriers and the axonal membrane. This may be influenced by local tissue binding, $\mathrm{pH}$, and 'spreading ability' of the agent. Volume and speed of injection, and local blood flow play a part. Addition of adrenaline prolongs action by reducing vascular absorption. The amides are metabolized in the liver, whil prilocaine is also metabolized in extra-hepatic tissues.

Blood concentration (and hence toxicity) of a local anaesthetic depends upon number of factors, including:

(1) site of injection and vascularity;

(2) differences in rates of distribution and/or metabolism. Prilocaine results in blood concentrations $25-50 \%$ of those for equivalent doses of lignocaine;

(3) dose-concentration is of greater importance than volume. Body weight, age and systematic disease are relevant;

(4) speed of injection;

(5) use of vasoconstrictor.

Local anaesthetic agents act non-selectively on axonal membranes of any nerve, by displacing calcium and initiating changes in conductance of the sodium channel, thus preventing generation of action potentials.

In nerve blockade, fibres are blocked in the following order:

B preganglionic autonomic, sympathetic;

AS pain/temperature;

C pain/temperature;

Ay proprioception;

$\mathrm{Ab}$ touch/pressure;

Aa motor.

Suggested local anaesthetic concentrations, doses and uses are listed in Table 2.

Toxicity of local anaesthetic agents is related to blood concentration, and is manifested principally as convulsions, or cardiovascular depression. Early signs of toxicity with lidocaine include circumoral numbness and drowsiness. 
Table 2 Commonly used local anaesthetics

\begin{tabular}{|c|c|c|c|}
\hline Agent & Concentration (\%) & Clinical use & Maximum single dose (mg) \\
\hline \multirow[t]{4}{*}{ Lignocaine } & $0 \cdot 5-1 \cdot 0$ & Infiltration or IV block & 300 (plain) \\
\hline & $1 \cdot 0-1 \cdot 5$ & Peripheral nerve block & 500 (adrenaline) \\
\hline & $1 \cdot 0-2 \cdot 0$ & Major plexus block & \\
\hline & $4 \cdot 0$ & Topical & \\
\hline \multirow[t]{3}{*}{ Prilocaine } & $0 \cdot 5-1 \cdot 0$ & Infiltration or IV block & 400 (plain) \\
\hline & $1 \cdot 0$ & Peripheral nerve block & 600 (adrenaline) \\
\hline & $2 \cdot 0-3 \cdot 0$ & Major plexus block & \\
\hline \multirow[t]{3}{*}{ Bupivacaine } & $0.25-0.5$ & Infiltration & \\
\hline & & Peripheral nerve block & 175 (plain) \\
\hline & $0.5-0.75$ & Major plexus & 250 (adrenaline) \\
\hline \multirow[t]{2}{*}{ Procaine } & $1 \cdot 0$ & Infiltration & 500 (plain) \\
\hline & & & 600 (adrenaline) \\
\hline
\end{tabular}

(Modified from Mather \& Phillips [1986].)

While prilocaine is the drug of choice for single dose intravenous blockade, because of its rapid metabolism (Holmes, 1980) lignocaine remains the most versatile drug for most surgical applications of short or medium duration, but adrenaline should be used to reduce vascular absorption, except where it is contraindicated.

\section{INHALATIONAL ANAESTHETIC AGENTS}

A number of inhaled gases and vapours have been used to produce analgesia. The most commonly used agents at present are nitrous oxide and methoxyflurane. Analgesia is produced when a certain brain concentration of the agent is achieved and this depends upon a number of factors, including:

(1) inhaled concentration of agent;

(2) alveolar ventilation;

(3) ventilation-perfusion matching;

(4) pulmonary perfusion;

(5) cerebral perfusion;

(6) blood/gas partition coefficient of the agent;

(7) tissue/blood partition coefficient of the agent;

(8) oil/gas partition coefficient of the agent.

Factors which result in rapid achievement of an effective analgesic brain concentration of an agent are inhalation of high concentration of the agent, production of a high minute volume of ventilation, or presence of a low cardiac output. Low blood/gas and oil/gas partition coefficients also increase the rate of equilibration of concentration of agent between brain and alveoli. 
Thus, an agent of low solubility such as nitrous oxide (blood/gas partition coefficient $\frac{\text { T }}{3}$ at $37^{\circ} \mathrm{C}$ is 0.47 ) is taken up slowly from the lungs by blood, and from blood by tissue. $\frac{\mathbb{Q}}{O}$ This results in a rapid rise of anaesthetic tension in both alveoli and brain. The reverse

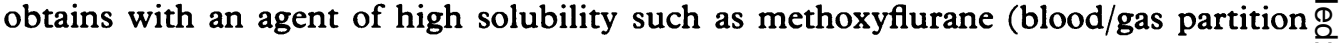
coefficient at $37^{\circ} \mathrm{C}$ is 13 ), because loss from alveoli into blood and from blood tissues slows the rise of agent tension in both alveoli and brain. When inhalation of the agent $\stackrel{\stackrel{5}{+}}{+}$ ceases, brain concentration falls as the agent is excreted from the alveoli.

Nitrous oxide is usually inhaled in the emergency department as a $50 \%$ concentration $\frac{\bar{O}}{\bar{c}}$ in oxygen (Entonox). Because of its low blood and tissue solubility, an effective $\frac{\widehat{\Phi}}{\Omega}$ analgesic concentration is reached within a few breaths, and any induced disturbance of conscious state is reversed within a few breaths of ceasing inhalation. Continuous $\vec{\circ}$ analgesia requires continuous inhalation.

Nitrous oxide has a mild cardiac depressant effect, and causes dilation of cerebral $\vec{\omega}$ vessels. It diffuses rapidly into air-containing spaces, as it replaces nitrogen, causing $\frac{\mathbb{D}}{3}$ expansion of air in bowel, pleural cavity, middle ear, cranial cavity, and air emboli.

Methoxyflurane, on the other hand, is highly soluble in both blood and fat. Effective brain analgesic concentrations are not achieved for some minutes following $\vec{p}$ commencement of inhalation, and analgesia persists for some minutes following $\stackrel{\supset}{-}$ cessation of inhalation. Its use in the emergency situation can thus be by intermittent inhalation once analgesia has been achieved.

Methoxyflurane has a mild cardiac depressant effect, and will depress respiration and cause renal failure in higher concentrations than are required for analgesia (Dripps et $\mathscr{\bullet}$ al., 1982).

It is important to appreciate that the effect of both agents is potentiated administration of opioids or other agents having a central nervous system depressarit effect.

\section{PRACTICAL IMPLICATIONS}

There are several methods available for relief of severe acute pain in the emergency department.

\section{Psychological Aspects}

Whatever method is chosen, patients respond better to its application if this is carried out in a positive and confident manner. Explanation of the nature of the problem, the measures being taken to correct it and the immediate outcome are important. Simple common-sense measures such as establishing good communication with the patient, understanding their concern, reassuring them that their anxiety is normal and

appropriately reinforcing their coping efforts all help pain relief.
If movement of the patient is required, they should be forewarned of the nature of the move and of the possibility or certainty of a transient increase in pain. Various forms of distraction or attention-diverson have been used to decrease pain and, where possible, $\stackrel{\mathscr{N}}{\rightarrow}$ patients should be encouraged to be actively involved in their care. 
Schwartz et al. (1984) have recently reported employment of re-education, stress management training and biofeedback in the treatment of a patient who presented to an emergency department with chest pain up to 20 times a month.

\section{Use of Opioids}

The most important points here are selection of an adequate dose of opioid and administration by an appropriate route:

For severe pain due to, for example, a crushing limb injury in an adult, administration of morphine intravenously in increments of $1 \mathrm{mg}(0.01 \mathrm{mg} / \mathrm{kg}$ for a child), pethidine $10 \mathrm{mg}(0 \cdot 1 \mathrm{mg} / \mathrm{kg}$ for a child) or fentanyl $10 \mathrm{mcg}(0 \cdot 1 \mathrm{mcg} / \mathrm{kg}$ for a child) should be continued until the patient is comfortable. This can be followed by further intravenous top-up doses by an intravenous infusion of the drug or by an intramuscular dose to maintain analgesia until definitive care has been planned and executed. Care should be taken to establish whether prior opioid administration has occurred, and the patient requires observation for side-effects of opioids. If a condition such as a head injury or respiratory failure coexists which contraindicates use of opioids, an alternative method of analgesia should be chosen. Vomiting due to opioid administration may require treatment with an anti-emetic, but these should not be given prophylactically.

\section{Use of Local Anaesthetics}

Local anaesthetics are used for many purposes in the emergency department: for infiltration of wounds, for nerve blocks, for topical application and for special purposes such as intravenous regional anaesthesia. While lignocaine in an appropriate concentration with adrenaline, unless contraindicated, is appropriate for most uses, special techniques demand special consideration.

Intravenous regional anaesthesia, originally described by Bier in 1908 using procaine, was popularized by Holmes in 1963 using lignocaine (Holmes, 1980). Because of a number of deaths associated with its use (Heath, 1982), it is now essential that a protocol be followed if it is to be used safely by junior staff. Such a protocol should make reference to the following points:

(1) intravenous access in the non-injured arm in case complications occur;

(2) exsanguination of the limb by bandage, or by elevation;

(3) inflation of an upper limb tourniquet to a pressure well in excess of systolic (e.g. 300 torr);

(4) use of a reliable cuff and pressure regulation system for safety;

(5) injection of an appropriate dose and dilution of a drug with low toxicity. $40 \mathrm{ml}$ of $0.5 \%$ plain prilocaine (maximum $3 \mathrm{mg} / \mathrm{kg}$ ) is most commonly used;

(6) release of cuff only after a minimum of 30 minutes has elapsed since injection;

(7) observation of the patient for at least 30 minutes following cuff release;

(8) insistence that one person is responsible for the anaesthesia alone;

(9) immediate availability of resuscitation equipment. 


\section{Inhalational Anaesthesia}

For practical purposes use of either nitrous oxide, methoxyflurane or any other inhalational analgesic in the emergency department should be confined to immediate, $\underset{\mathbb{0}}{\overrightarrow{\mathrm{d}}}$ reversible analgesia until diagnoses are established and a decision made about use of a longer acting method.

\section{CONCLUSION}

Severe acute pain in the emergency department should be managed by means appropriate to the particular problem in the particular patient. Appropriate pain management should be supplemented by inhalational agents, opioids or local anaesthetics as indicated. Choice of agent, dose and technique should depend upon the patient's age, size and personality, the cause, severity and nature of the pain, whether or not an operative procedure is required, whether or not the patient will be admitted, and the patient's pre-existing medical condition.

Choice of drug should be based on a knowledge of its pharmacodynamic and pharmacokinetic properties, while choice of technique should take into account the problem presented by the patient, the skill of the operator and the particular complications likely in the particular environment.

Appropriate use of pain-relieving techniques makes it possible to relieve severe paim $\stackrel{\circ}{\circ}$ without interfering with diagnosis.

\section{ACKNOWLEDGEMENTS}

We would like to thank Professor Michael Cousins for his help and encouragement, and Mrs Marion Wallace for typing the manuscript.

\section{G. D. PHILLIPS and C. J. BAGGOLEY}

Department of Accident and Emergency Medicine, and Anaesthesia and Intensive Care, Flinders Medical Centre, Adelaide, Australia

\section{REFERENCES}

Beecher H. K. (1945) Pain in men wounded in battle. Annals of Surgery 123, 96-105.

Beecher H. K. (1956) Relationship of significance of wound to pain experienced. fournal of the American Medical Association 161, 1609-13.

Bullingham R. E. S., McQuay N. J. \& Moore R. A. (1983) Clinical pharmacokinetics of narcotic agonist/antagonist drugs. Clinical Pharmacokinetics 8, 332-43. 
Coggeshall R. E., Applebaum M. L., Fazen M., Stubbs T. B. III \& Sykes M. T. (1975) Unmyelinated axons in human ventral roots, a possible explanation for the failure of dorsal rhizotomy to relieve pain. Brain 98, 157-66.

Dripps R. D., Eckenhoff J. E. \& Vandam L. D. (1982) Introduction to anesthesia. Philadelphia, WB Saunders Company.

Gourlay G. K. \& Cousins M. J. (1984) Strong analgesics in severe pain. Drugs 28, 79-91.

Heath M. L. (1982) Deaths after intravenous regional anaesthesia. British Medical fournal 285, 913-14.

Holmes C. McK. (1980) Intravenous regional neural blockade. In Neural Blockade in Clinical Anaesthesia and Pain Management, Cousins M. J. \& Bridenbaugh P. O. (eds). Pp 343-54. JB Lippincott, Philadelphia.

Juan H. (1978) Prostaglandins as modulators of pain. fournal of General Pharmacology 9, 403.

Ling G. S. F., Spiegel K., Nishimura S. L. \& Pasternak G. W. (1983) Dissociation of morphine's analgesic and respiratory depressant actions. European fournal of Pharmacology 86, 487.

Mather L. E. (1983) Clinical pharmacokinetics of fentanyl and its newer derivatives. Clinical Pharmacokinetics 8, 422-46.

Mather L. E. \& Cousins M. J. (1979) Local anaesthetics and their current use. Drugs 18, 185-205.

Mather L. E. \& Phillips G. D. (1986) Opioids and adjuvants in acute pain management. In Acute Pain Management, Cousins M. J. \& Phillips G. D. (eds). Pp 77-104. Clinics in Critical Care Medicine. New York, Churchill Livingstone.

Melzack R. \& Wall P. D. (1965) Pain mechanisms. A new theory. Science 150, 971-9.

Melzack R., Wall P. D. \& Ty T. C. (1982) Acute pain in an emergency clinic: latency of onset and descriptor patterns related to different injuries. Pain 14, 33-44.

Paterson S. J., Robson L. E. \& Kosterlitz H. W. (1983) Classification of opioid receptors. British Medical Bulletin 39, 31-6.

Peck C. L. (1986) Psychological factors in acute pain management. In Acute Pain Management, Cousins M. J. \& Phillips G. D. (eds). Pp 251-74. Clinics in Critical Care Medicine, New York, Churchill Livingstone.

Phillips G. D. \& Cousins M. J. (1986) Neurologic mechanisms of pain and the relationship of pain, anxiety, and sleep. In Acute Pain Management, Cousins M. J. \& Phillips G. D. (eds). Pp 21-48. Clinics in Critical Care Medicine. New York, Churchill Livingstone.

Rosow C. E. (1985) Newer synthetic opioid analgesics. In Acute Pain, Smith \& Covino B. G. (eds). Pp. 68-103. Butterworths, London.

Schwartz D. P., Lange H. S., DeGood D. E., Wegener S. T. \& Rowlingson J. C. (1984) A chronic emergency room visitor with chest pain: successful treatment by stress management training and biofeedback. Pain 18, 315-9.

Zukin R. \& Zukin S. R. (1981) Multiple opiate receptors: emerging concepts. Life Sciences 2, 2681-90. 